\title{
Single-wall carbon nanotubes improve cell survival rate and reduce oxidative injury in cryopreservation of Agapanthus praecox embryogenic callus
}

\author{
Li Ren $^{1+} \mathbb{0}$, Shan Deng ${ }^{1 \dagger}$, Yunxia Chu' ${ }^{1}$, Yiying Zhang ${ }^{1}$, Hong Zhao ${ }^{1}$, Hairong Chen ${ }^{1 *}(1)$ and Di Zhang ${ }^{2^{*}}$
}

\begin{abstract}
Background: Cryopreservation is the best way for long-term in vitro preservation of plant germplasm resources. The preliminary studies found that reactive oxygen species (ROS) induced oxidative stress and ice-induced membrane damage are the fundamental causes of cell death in cryopreserved samples. How to improve plant cryopreservation survival rate is an important scientific issue in the cryobiology field.

Results: This study found that the survival rate was significantly improved by adding single-wall carbon nanotubes (SWCNTs) to plant vitrification solution (PVS) in cryopreservation of Agapanthus praecox embryogenic callus (EC), and analyzed the oxidative response of cells during the control and SWCNTs-added cryopreservation protocol. The SWCNTs entered EC at the step of dehydration and mainly located around the cell wall and in the vesicles, and most of SWCNTs moved out of EC during the dilution step. Combination with physiological index and gene quantitative expression results, SWCNTs affect the ROS signal transduction and antioxidant system response during plant cryopreservation. The EC treated by SWCNTs had higher antioxidant levels, like POD, CAT, and GSH than the control group EC. The EC mainly depended on the AsA-GSH and GPX cycle to scavenge $\mathrm{H}_{2} \mathrm{O}_{2}$ in the control cryopreservation, but depended on CAT in the SWCNTs-added cryopreservation which lead to low levels of $\mathrm{H}_{2} \mathrm{O}_{2}$ and MDA. The elevated antioxidant level in dehydration by adding SWCNTs enhanced cells resistance to injury during cryopreservation. The ROS signals of EC were balanced and stable in the SWCNTs-added cryopreservation.
\end{abstract}

Conclusions: The SWCNTs regulated oxidative stress responses of EC during the process and controlled oxidative damages by the maintenance of ROS homeostasis to achieve a high survival rate after cryopreservation. This study is the first to systematically describe the role of carbon nanomaterial in the regulation of plant oxidative stress response, and provided a novel insight into the application of nanomaterials in the field of cryobiology.

Keywords: Agapanthus praecox, Cryopreservation, Oxidative stress, Single-wall carbon nanotubes

*Correspondence: saasdus@163.com; zhangdi2013@sjtu.edu.cn

†'Li Ren and Shan Deng contributed equally to this work

${ }^{1}$ Institute for Agri-food Standards and Testing Technology,

Shanghai Academy of Agricultural Sciences, NO. 888, Rd. Yezhuang,

Shanghai 201403, China

2 Department of Landscape Science and Engineering, School of Design, Shanghai Jiao Tong University, NO. 800, Rd. Dong Chuan,

Shanghai 200240, China

\section{Background}

The long-term preservation of plants in vitro cultures of cell cultures, embryogenic materials, and endangered germplasm is a vital requirement around the world [1]. Cryopreservation, the storage of living cells, tissues, organs or whole plants in extra low temperature, such as in liquid nitrogen (LN), is thought to be the ideal method to realize the safe and cost-efficient medium- and

(c) The Author(s) 2020. This article is licensed under a Creative Commons Attribution 4.0 International License, which permits use, sharing, adaptation, distribution and reproduction in any medium or format, as long as you give appropriate credit to the original author(s) and the source, provide a link to the Creative Commons licence, and indicate if changes were made. The images or other third party material in this article are included in the article's Creative Commons licence, unless indicated otherwise in a credit line to the material. If material is not included in the article's Creative Commons licence and your intended use is not permitted by statutory regulation or exceeds the permitted use, you will need to obtain permission directly from the copyright holder. To view a copy of this licence, visit http://creativecommons.org/licenses/by/4.0/. The Creative Commons Public Domain Dedication waiver (http://creativecommons.org/publicdomain/zero/1.0/) applies to the data made available in this article, unless otherwise stated in a credit line to the data. 
long-term preservation of almost all economically important crops [2-4]. Vitrification-based cryopreservation has been successfully applied to long-term preservation by achieving the glassy state in cryopreservation of many plant species for its rapid and convenient procedure [5]. Plant vitrification solution (PVS), a commonly used cryoprotectant in vitrification-based cryopreservation, can replace cellular water, alter the freezing behavior, and prevent ultra-water loss [6].

Vitrification-based cryopreservation achieves the storage by enhancing cell viscosity, and accompanies many stresses leading to the accumulation of reactive oxygen species (ROS) [7]. ROS-induced oxidative stress is the fundamental trigger of cell death during cryopreservation [8]. Ren et al. [7, 9] utilized comparative transcriptomics to obtain genes responses to cryoinjury and revealed that peroxidation was a key element affecting viability, and genes related to oxidative stress played important roles in Arabidopsis thaliana cryopreservation. Zhang et al. [10] revealed that the oxidative stress and apoptosis were the major factors that injure embryogenic callus (EC) during Agapanthus praecox cryopreservation.

Plants have complex antioxidant systems including antioxidant enzymes, such as catalase (CAT), superoxide dismutase (SOD), glutathione reductase (GR) and ascorbate peroxidase (APX), and non-enzymatic antioxidants, like glutathione (GSH) and ascorbic acid (AsA) [11]. The high antioxidant level is related to the tolerance to cryopreservation [12]. In antioxidant enzymes, SOD removes $\mathrm{O}_{2}{ }^{-}$to $\mathrm{H}_{2} \mathrm{O}_{2}$, and CAT catalyzes $\mathrm{H}_{2} \mathrm{O}_{2}$ to $\mathrm{O}_{2}$ and $\mathrm{H}_{2} \mathrm{O}$ $[13,14]$. In non-enzymatic antioxidants, AsA and GSH helps keep a normal REDOX state to counteract oxidative damages [15].

Many researchers have been focusing on the improvement of the cryopreservation procedure by adding exogenous compounds to the cryoprotectant to reduce damages. Nanomaterials have a good effect to improve the cryoprotectant, due to its small particle size and large specific surface [16]. After adding nanomaterials to the cryoprotectant can enhance the thermal conductivity and relative viscosity, promote vitrification, improve the stability of solution during the rewarming process, and suppress the occurrence of devitrification [17-19]. Han et al. [20] added $0.2 \%$ Nano-diamond to the ethylene glycol cryoprotectant, and found it doubled the freezing rate and decreased the glass transition temperature significantly. In addition, adding $0.05 \%$ hydroxyapatite to the cryoprotectant can improve the pig oocytes developmental rate from $14.7 \%$ to $30.4 \%$ after cryopreservation [19, 21]. After adding Nanomaterials Rhodiola Sachanensis Polysaccharide (NRSP), the motility, acrosome integrity and membrane integrity of boar sperm were improved significantly compared to the control groups after freezing and thawing [22]. With the addition of NRSP in the cryoprotectant, the malondialdehyde (MDA) content decreased and the activity of SOD increased [21]. Furthermore, lecithin nanoparticles can enhance the cryosurvival of caprine sperm [23], and albumin coated copper-cysteine nanozyme and Au-Ag-AFT nanozyme both can improve survival of human sperm after cryopreservation by reducing oxidative stress [24, 25]. Enrichment of semen extender with selenium nanoparticles improved fertility rate through decreasing peroxidation and injury during cryopreservation of Holstein bulls [26].

However, some nanomaterials have been reported to induce cell death $[17,18]$, and carbon nanomaterials (CNMs) have better biosafety and biocompatibility [27, 28]. 60-h seedlings of Arabidopsis thaliana are often used as an experimental model to evaluate the optimal effect of exogenous additives on cryopreservation of plants [7]. In our previous studies, CNMs including graphene, single-walled carbon nanotubes (SWCNTs) and graphene quantum dots have been applied in this cryopreservation model to identify their effects on cryopreservation, and $0.1 \mathrm{~g} / \mathrm{L}$ SWCNTs in PVS2 was the most effective one (unpublished results). Then we applied it to the callus or protocorm cryopreservation of lily, Cymbidium and Anoectochilu, and it also played a positive role in each process. Chen et al. [28] investigated the efficiency of SWCNTs, Graphene, Graphene quantum dots and fullerene $\left(C_{60}\right)$ on the cryopreservation of Agapanthus praecox callus by adding to PVS2. $0.3 \mathrm{~g} / \mathrm{L}$ fullerene and $0.1 \mathrm{~g} / \mathrm{L}$ SWCNTs were the best two CNMs. The effect on vitrification behaviors was detected, and the glass transition temperatures showed no significant difference on Nano-PVS2. Raman spectroscopy and transmission electron microscopy (TEM) analyses demonstrated that the SWCNTs and fullerene were able to enter the callus cells and protect the cell structure [28].

Agapanthus praecox is a perennial herbaceous plant from Agapanthaceae family and is endemic to southern Africa $[29,30]$. A. praecox is known for its ornamental and medicinal values. It is popular as the potted plant, cut flower, and landscape plant due to its multiflorous character, long flowering duration, and wide spectrum of colors [30, 31]. It contains various bioactive compounds such as saponins and chalconoids, which possess anti-inflammatory, antitussive, immunoregulatory, and antibacterial properties [32]. Some rapid micropropagation protocols for clonal propagation and conservation purposes were reported including the induction of EC [33-35]. The EC is an important germplasm resource, but somatic embryogenic ability is often lost during longterm subculture. Cryopreservation is an effective way to solve this problem. Generally, seeds, with characteristic dense cytoplasm and low water content, are easily 
cryopreserved by vitrification. However, callus cultures, suspension cultures, shoot tips, and recalcitrant seeds are more difficult to cryopreserve due to their higher water content, active metabolic activities, complex biological processes, and sensitive stress responses [7, 10]. A. praecox $\mathrm{EC}$ is representatively cryoinjury-susceptible materials for its high moisture content and low-temperature sensitivity [30]. In previous, we have initially cryopreserved the EC of $A$. praecox. In this study, SWCNTs adding into PVS2 evaluated the survival rate of EC after cryopreservation. It aims to point the positive effects to oxidative stress in cryopreservation, and provides a new application of CNMs using as protectants during cryopreservation. This study is the first time to systematically investigate the effects of nanomaterial to regulate cell responses to oxidative stress in plant cryopreservation applications.

\section{Results}

\section{Effects of SWCNTs on the cell viability} after cryopreservation

Based on the previous studies, CNMs have been applied in the Arabidopsis cryopreservation model to identify their effects on cryopreservation, and $0.1 \mathrm{~g} / \mathrm{L}$ SWCNTs in PVS2 was the most effective one (unpublished results). In this study, we applied it to the EC cryopreservation of A. praecox, and $0.1 \mathrm{~g} / \mathrm{L}$ SWCNTs have improved the relative survival rate from $53.42 \%$ to $84.57 \%$ (Fig. 1). Comparing it to the effects of other compounds adding to PVS2 in previous studies including $0.08 \mathrm{mM}$ GSH, $1 \mu \mathrm{M}$ abscisic acid (ABA), $0.1 \mu \mathrm{M}$ melatonin, $1 \mathrm{mM}$ AsA, $10 \mathrm{mM}$ betaine, $1 \mathrm{mM} \mathrm{CaCl}_{2}, 6 \mathrm{mM}$ lipoic acid (LA), $6 \mathrm{mM}$ polyvinyl alcohol (PVA), or 3\% polyvinyl pyrrolidone (PVP), $0.1 \mathrm{~g} / \mathrm{L}$ SWCNTs had a significant effect on the EC survival increasing by $58.31 \%$ higher than others (Fig. 1).

\section{Localizations of SWCNTs in EC during cryopreservation}

Transmission electron microscopy imaging provided accurate results, which displayed the cellular status of EC and localizations of SWCNTs inside the EC. Many mitochondria, Golgi apparatus, and endoplasmic reticulum distributed in the EC with complete and compact cell structure before cryopreservation (Fig. 2a, b). After pre-culture, mitochondria, and cell membrane exhibited slight contraction in EC (Fig. 2c, d). The SWCNTs entered EC at the step of dehydration, and mainly located around the cell wall and in the vesicles (Fig. 2e-h). It is demonstrated that plasmolysis, protoplast concentrated, organelles damage and more intracellular vesicles were observed after dehydration (Fig. 2h). The dilution treatment caused most of SWCNTs to move out of EC, and the retained SWCNTs were mostly tube-like fragmented, mainly distributed in the cytoplasm and vesicles (Fig. 2i-l).

\section{Effects of SWCNTs on the ROS and MDA contents during cryopreservation}

In the control procedure, $\mathrm{H}_{2} \mathrm{O}_{2}$ contents highly increased in dehydration and reached the peak after rapid coolingwarming, which was more than twofold compared with CK (Fig. 3a). Adding SWCNTs could inhibit $\mathrm{H}_{2} \mathrm{O}_{2}$ content during the dehydration step, and $\mathrm{H}_{2} \mathrm{O}_{2}$ content kept

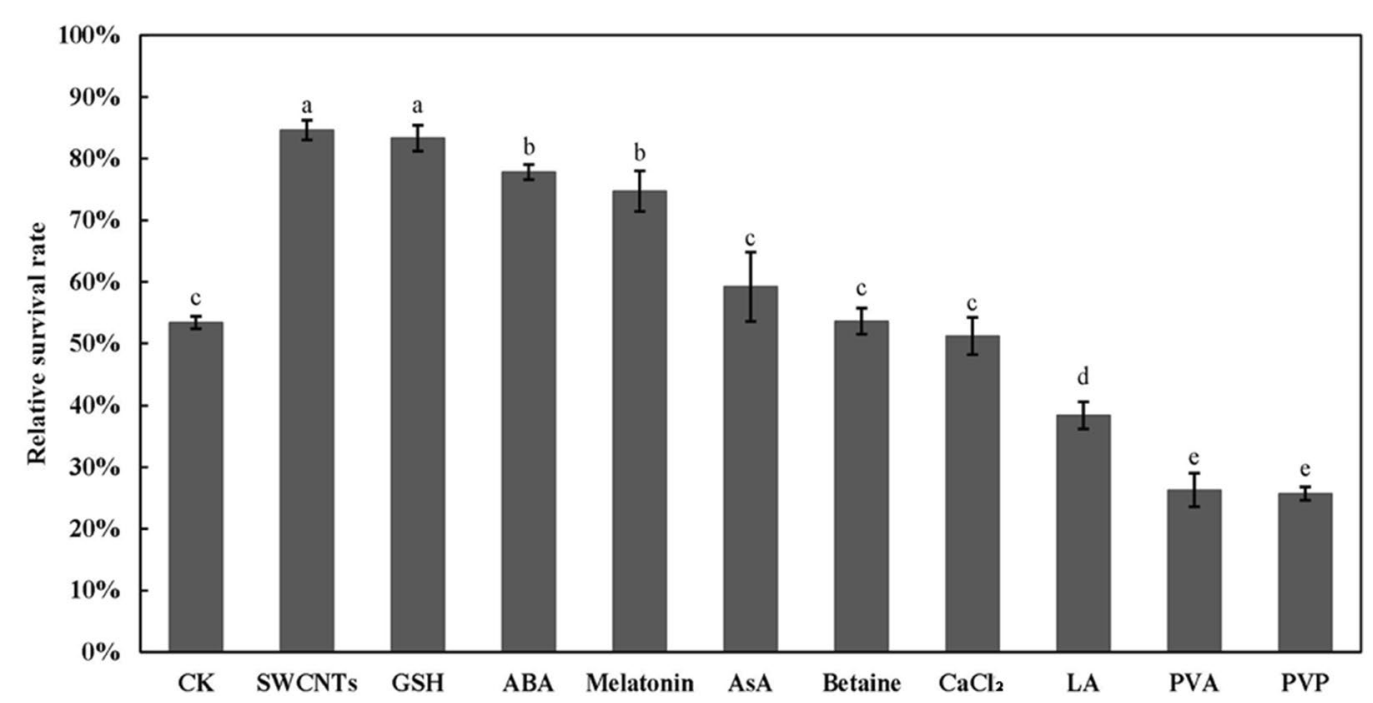

Fig. 1 Effects of different exogenous substances on the survival rate of Agapanthus praecox EC cryopreservation. Concentration of exogenous substances added are: $0.1 \mathrm{~g} / \mathrm{L}$ SWCNTs, $0.08 \mathrm{mM} \mathrm{GSH}, 1 \mu \mathrm{M} \mathrm{ABA}, 0.1 \mu \mathrm{M}$ melatonin, $1 \mathrm{mM}$ AsA, $10 \mathrm{mM}$ betaine, $1 \mathrm{mM} \mathrm{CaCl}, 6 \mathrm{mM} \mathrm{LA}, 6 \mathrm{mM} \mathrm{PVA}, 3 \%$ PVP. Values with different small letters are significantly different between different treatment at 0.05 level 

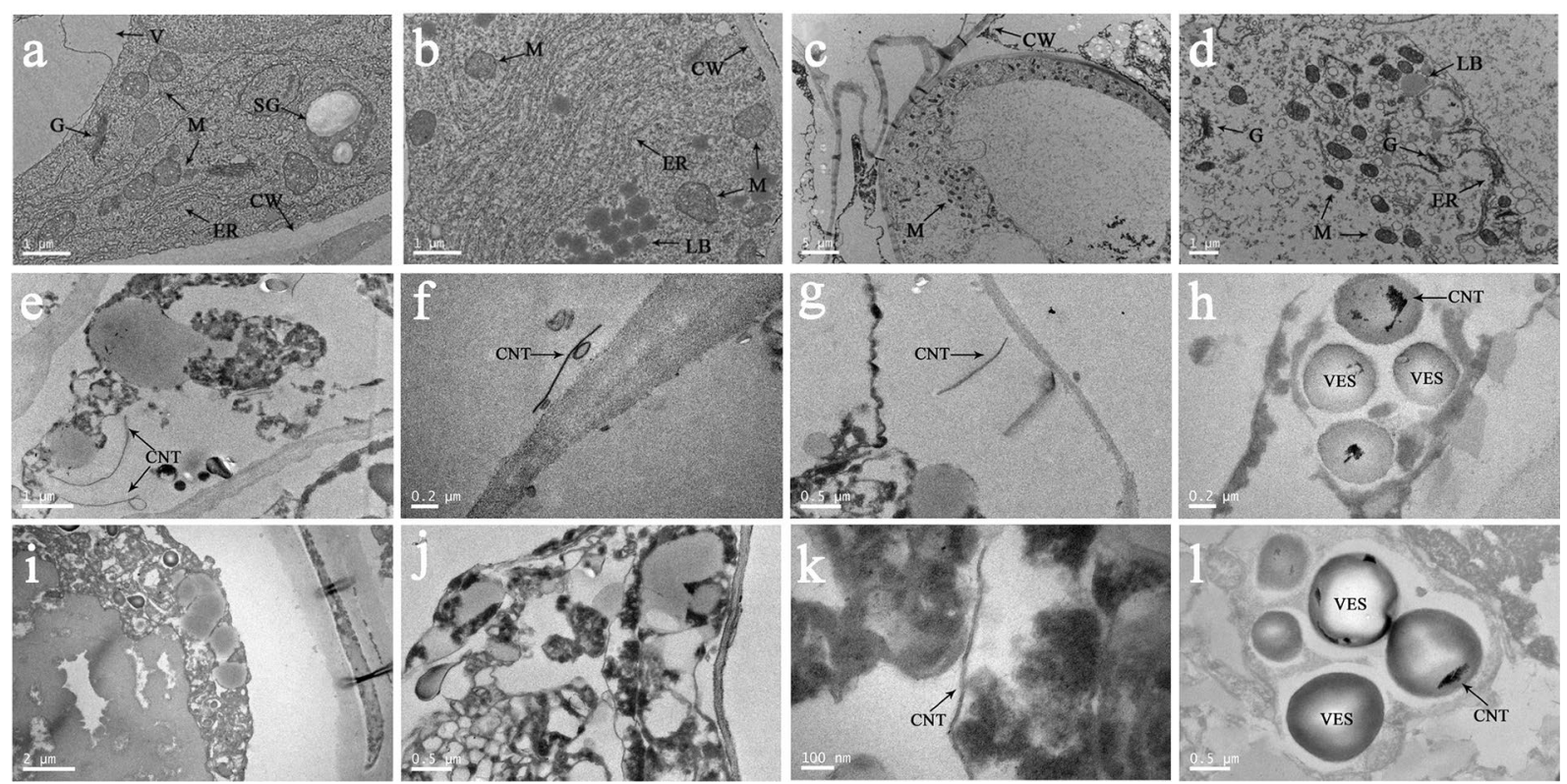

Fig. 2 Cell ultrastructure observation of Agapanthus praecox during the SWCNTs-added cryopreservation. $\mathbf{a}$, $\mathbf{b}$ the EC before cryopreservation, $\mathbf{c}$, d the EC after pre-culture, $\mathbf{e}-\mathbf{h}$ the EC after dehydration, $\mathbf{i}-\mathbf{I}$ the EC after dilution. Cell wall (CW), endoplasmic reticulum (ER), golgi apparatus (G), lipid body (LB), mitochondrion (M), starch grains (SG), vesicle (VES)

at a low level in rapid cooling-warming and decreased significantly in dilution in the improved cryopreservation. $\mathrm{O}_{2}^{-}$inhibitation activities were higher in all steps of the control group, and $\mathrm{OH}$. generation activities were higher after rapid cooling-warming in the SWCNTsadded cryopreservation (Fig. 3b, c). The MDA content trend was similar to that of $\mathrm{H}_{2} \mathrm{O}_{2}$. The MDA accumulation increased apparently during the control cryopreservation, and the EC treated with SWCNTs had less MDA than in control through the whole procedure (Fig. 3d).

\section{Effects of SWCNTs on the antioxidant system during cryopreservation}

Adding SWCNTs significantly increased the activity of the antioxidant system during cryopreservation. With the addition of SWCNTs to the PVS2, the activities of enzymatic antioxidants highly increased, especially POD and CAT activities (Fig. 3f, g). The changes of SOD activity were not significant (Fig. 3e). The increases of POD activity treated by SWCNTs were much greater than those in the control process (Fig. 3f). Furthermore, the non-enzymatic antioxidant GSH in the SWCNTs group increased nearly twofold compared to the control group during dehydration (Fig. 3i).

\section{Correlation analysis of oxidative physiological indices}

In the control cryopreservation (Table 1), MDA contents showed a significant positive correlation with $\mathrm{H}_{2} \mathrm{O}_{2}$ contents, which revealed that peroxidation was mainly caused by $\mathrm{H}_{2} \mathrm{O}_{2}$ in EC during cryopreservation. At the same time, $\mathrm{OH}$. generation activities had a significant positive correlation with $\mathrm{H}_{2} \mathrm{O}_{2}$ and MDA contents. SOD activities had a significant positive correlation with CAT activities and AsA contents. In the SWCNTs cryopreservation (Table 2), $\mathrm{O}_{2}{ }^{-}$inhibitation activities had a significant negative correlation with POD activities, MDA and AsA contents, and $\mathrm{OH}$. generation activities had a significant positive correlation with SOD activities and AsA contents. MDA contents had a significant positive correlation with SOD activities, and SOD activities had a significant positive correlation with AsA contents like in the control cryopreservation. In addition, there was a significant positive correlation between POD and CAT activities indicating that the two enzymes may work together to decrease the ROS level during cryopreservation.

\section{Quantitative expression analysis of genes related to oxidative stress response}

Some genes related to oxidative stress response were chosen to study the molecular protection of SWCNTs during cryopreservation (Figs. 4, 5). As a ROS signal transduction related gene, oxidative signal-inducible 1 (OXI1) was significantly upregulated at rapid cooling-warming stage in the control group, but maintained a low expression level in the SWCNTs group. MAPK3/6 is located downstream of OXI1, and their expression patterns were 

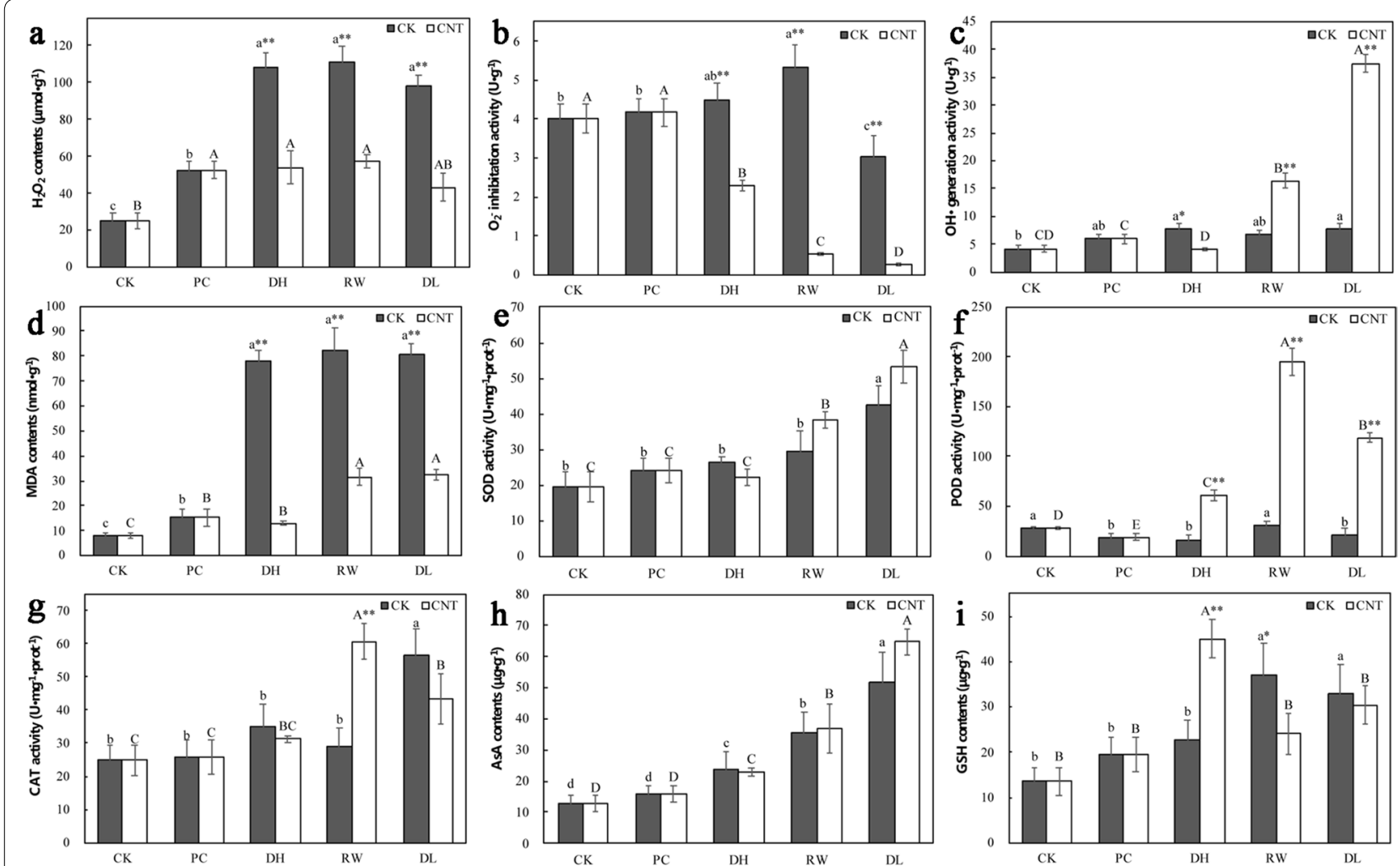

Fig. 3 Physiological indices detection of SWCNTs added in cryopreservation system. Physiological indices were determined with at least three repeats. Bars represent means and standard deviation over triplicate detection. Values with different lowercase letters are significantly different among samples in the control group at 0.05 level. Values with different uppercase letters are significantly different among samples in the SWCNTs group at 0.05 level. * are significantly different between different groups in the same stage at 0.05 level, and ** are highly significantly different between different groups in the same stage at 0.01 level. The CK group is the cryopreservation without adding SWCNTs, and the CNT group is the SWCNTs-added cryopreservation. CK, untreated; PC, after pre-culture; $\mathrm{DH}$, after dehydration; RW, after rapid cooling-warming; $\mathrm{DL}$, after dilution

Table 1 The correlation analysis of physiological indices in the control cryopreservation

\begin{tabular}{|c|c|c|c|c|c|c|c|c|c|}
\hline Indices & $\mathrm{H}_{2} \mathrm{O}_{2}$ & $\begin{array}{l}\mathrm{O}_{2}^{-} \\
\text {inhibitation } \\
\text { activity }\end{array}$ & $\begin{array}{l}\mathrm{OH} \text {. } \\
\text { generation } \\
\text { activity }\end{array}$ & MDA & SOD & POD & CAT & AsA & GSH \\
\hline $\mathrm{H}_{2} \mathrm{O}_{2}$ & 1 & 0.263 & $0.918^{*}$ & $0.974^{* *}$ & 0.630 & -0.141 & 0.510 & 0.702 & 0.830 \\
\hline $\mathrm{O}_{2}^{-}$inhibitation activity & & 1 & -0.076 & 0.146 & -0.477 & 0.381 & -0.678 & -0.319 & 0.190 \\
\hline $\mathrm{OH} \cdot$ generation activity & & & 1 & $0.888^{*}$ & 0.764 & -0.447 & 0.709 & 0.747 & 0.718 \\
\hline MDA & & & & 1 & 0.707 & -0.046 & 0.621 & 0.794 & 0.844 \\
\hline SOD & & & & & 1 & -0.107 & $0.935^{*}$ & $0.973^{* *}$ & 0.764 \\
\hline POD & & & & & & 1 & -0.277 & 0.075 & 0.269 \\
\hline CAT & & & & & & & 1 & 0.878 & 0.527 \\
\hline AsA & & & & & & & & 1 & 0.859 \\
\hline GSH & & & & & & & & & 1 \\
\hline
\end{tabular}

All the data were correlation coefficients, and significant levels are indicated at ${ }^{*} \mathrm{P}<0.05$ or ${ }^{* *} \mathrm{P}<0.01$

very similar to that of OXI1. As a ROS signal amplification related gene, NADPH oxidase (RbohA) maintained a low expression level in the control group, and was significantly upregulated after dehydration in the SWCNTs group.

In the ROS-scavenging network, SOD and CAT catalyzed $\mathrm{O}_{2}{ }^{-}$by forming $\mathrm{H}_{2} \mathrm{O}_{2}$ and $\mathrm{H}_{2} \mathrm{O}$, respectively. The 
Table 2 The correlation analysis of physiological indices in the SWCNTs-added cryopreservation

\begin{tabular}{|c|c|c|c|c|c|c|c|c|c|}
\hline Indices & $\mathrm{H}_{2} \mathrm{O}_{2}$ & $\begin{array}{l}\mathrm{O}_{2}^{-} \\
\text {inhibitation } \\
\text { activity }\end{array}$ & $\begin{array}{l}\mathrm{OH} \cdot \\
\text { generation } \\
\text { activity }\end{array}$ & MDA & SOD & POD & CAT & AsA & GSH \\
\hline $\mathrm{H}_{2} \mathrm{O}_{2}$ & 1 & -0.388 & 0.042 & 0.440 & 0.195 & 0.451 & 0.490 & 0.166 & 0.529 \\
\hline $\mathrm{O}_{2}^{-}$inhibitation activity & & 1 & -0.793 & $-0.904^{*}$ & -0.864 & $-0.894^{*}$ & -0.867 & $-0.884^{*}$ & -0.437 \\
\hline $\mathrm{OH} \cdot$ generation activity & & & 1 & 0.851 & $0.982^{* *}$ & 0.568 & 0.550 & $0.979 * *$ & 0.124 \\
\hline MDA & & & & 1 & $0.934^{*}$ & 0.868 & 0.875 & 0.877 & 0.147 \\
\hline SOD & & & & & 1 & 0.693 & 0.683 & $0.980^{* *}$ & 0.152 \\
\hline POD & & & & & & 1 & $0.996^{* *}$ & 0.647 & 0.175 \\
\hline CAT & & & & & & & 1 & 0.621 & 0.134 \\
\hline AsA & & & & & & & & 1 & 0.304 \\
\hline GSH & & & & & & & & & 1 \\
\hline
\end{tabular}

All the data were correlation coefficients, and significant levels are indicated at ${ }^{*} \mathrm{P}<0.05$ or $*{ }^{*} \mathrm{P}<0.01$

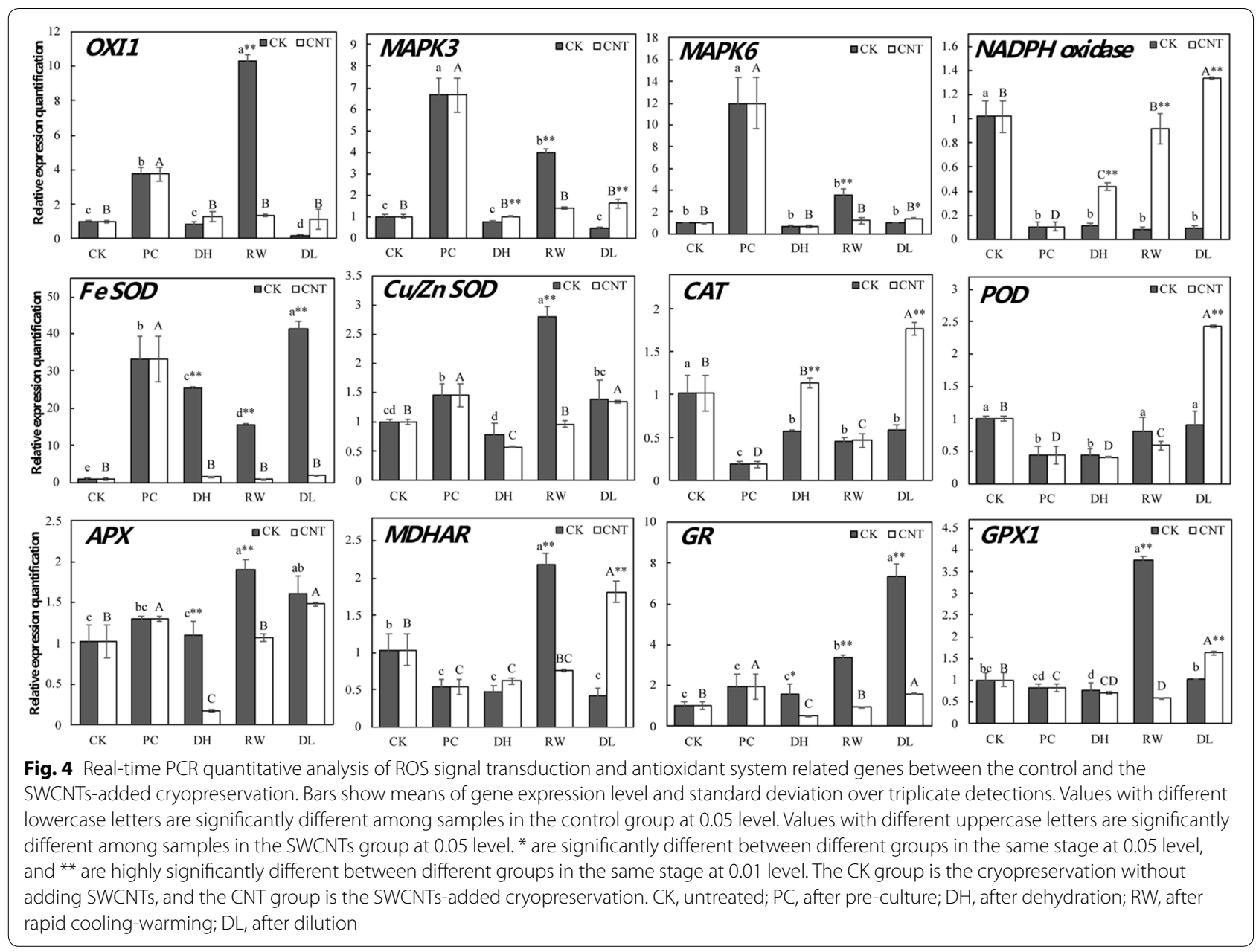

expression levels of $\mathrm{Cu} / \mathrm{Zn}$ and $\mathrm{Fe} S O D$ were higher in the control group than SWCNTs group, but those of $C A T$ were quite the opposite which shown that CAT was upregulated in SWCNTs group. The glutathione peroxidase (GPX) and AsA-GSH cycle were also essential to scavenge $\mathrm{H}_{2} \mathrm{O}_{2}$. Glutathione reductase (GR) and GPX drive the GPX cycle, and GR, monodehydroascorbate reductase (MDHAR), and ascorbate peroxidase (APX) 


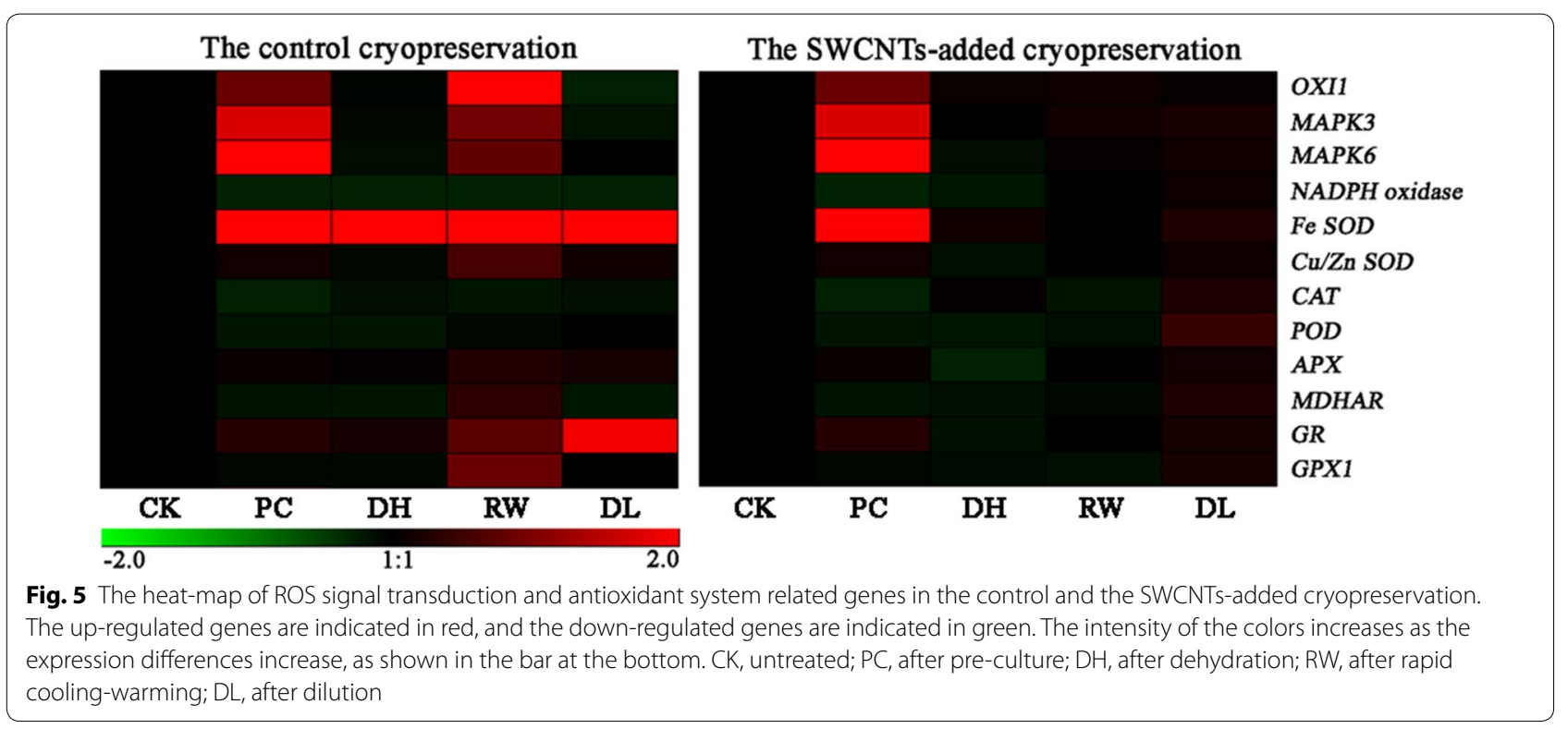

regulate the AsA-GSH cycle. The expression levels of GR and $A P X$ were higher in the control group than SWCNTs group. The expression patterns of GPX1 and MDHAR had the similar trend. They were only significantly upregulated in the rapid cooling-warming step of the control cryopreservation, and the dilution step of the SWCNTs cryopreservation. POD only significantly upregulated in the dilution step of the SWCNTs cryopreservation.

\section{Discussion}

\section{SWCNTs contribute to the better efficiency} of cryoprotectant

The field of plant cryobiology seeks to modify existing techniques that allow for the more efficient storage by reducing multiple stresses. Adding some exogenous compounds can improve the survival of cryopreserved cells in many species, like antioxidants [30, 36-39], anti-stress compounds $[40,41]$, metabolism related compounds [42, $43]$ and ice inhibitors [44, 45]. Previously we found that CNMs especially SWCNTs adding to PVS2 can improve the survival rate of Arabidopsis seedlings, callus or protocorm of lily, Cymbidium and Anoectochilu (unpublished results) and $A$. praecox callus [28] after cryopreservation. In this study, the relative survival rate was highly improved by adding SWCNTs to PVS2 in cryopreservation of $A$. praecox EC compared to the above compounds (Fig. 1). Thus, SWCNTs are the potential and important exogenous additions of cryoprotectant.

In our previous study, the differential scanning calorimetry (DSC) analysis suggested that the glass-transition temperature of SWCNTs-PVS2 slightly decreased [28]. Adding $0.1 \mathrm{~g} / \mathrm{L} \mathrm{SWCNTs}$ to PVS2 reduced the glass-transition temperature from -112.67 to $-114.18{ }^{\circ} \mathrm{C}$ still within the reported temperature range of PVS2 $\left(-115{ }^{\circ} \mathrm{C}\right.$ to $\left.-112^{\circ} \mathrm{C}\right)$. Moreover, a melting peak around $-38.87{ }^{\circ} \mathrm{C}$ and an endothermic peak at $-50.12{ }^{\circ} \mathrm{C}$ were observed in the DSC curve of $0.1 \mathrm{~g} / \mathrm{L}$ SWCNTs-PVS2. It indicated that SWCNTs-PVS2 may be more stable than PVS2, but no significant changes on glass transition parameters were detected [28]. Since the glass-transition temperature is not significantly changed, do SWCNTs regulate the physiological response of plant cells?

\section{Effective antioxidant response during the dehydration step} improved EC survival after cryopreservation

ROS-induced oxidative stress is a major reason of low survival in samples after cryopreservation [10, 46-53]. In many species cryopreservation, $\mathrm{H}_{2} \mathrm{O}_{2}$ is the major component of ROS leading to oxidative stress [8,50]. Adding SWCNTs in the cryoprotectant might suppress $\mathrm{H}_{2} \mathrm{O}_{2}$ production and maintain the $\mathrm{H}_{2} \mathrm{O}_{2}$ content in the lower level than that in the control process, in which $\mathrm{H}_{2} \mathrm{O}_{2}$ content increased dramatically otherwise.

Membrane lipids are the primary target in oxidative damage [54], and MDA acting as a breakdown product of lipid peroxidation increased in cryopreserved Oryza sativa [52, 55], Azadirachta indica [56], Arabidopsis thaliana [8], Agapanthus praecox [10], Hancornia speciose [57], and Passiflora suberosa [53]. With the addition of NRSP in the cryoprotectant, the MDA content decreased and the SOD activity increased leading to more intact membrane and better quality of boar sperm [21]. The MDA content significantly increased in the 
control process, and led to the low survival rate of EC after cryopreservation.

The antioxidant system works to prevent plant cells from oxidative injury through cleaning ROS [11]. SWCNTs can activate related antioxidant enzymes, and improve survival after cryopreservation. In general, antioxidant enzyme activities increased after rapid coolingwarming (Fig. 3). In the SWCNTs cryopreservation, the enzyme activities rose up when cells were treated with SWCNTs-added PVS2, and maintained in a relative high level through the process. Like CAT was involved in scavenging the intracellular $\mathrm{H}_{2} \mathrm{O}_{2}$ in the SWCNTs-treated group, it is also found that cryopreserved of Dendrobium suffered serious oxidative stress because of decreasing CAT activity after cryopreservation leading to low survival [58], and high tolerance was related to high CAT activity in Haematococcus pluvialis cryopreservation [59]. In the study of Liu [60], the graphene-treated rice produced oxidative stress response, and the activities of SOD, POD and CAT were all increased in seedlings treated with graphene.

AsA-GSH cycle is a key way to scavenge $\mathrm{H}_{2} \mathrm{O}_{2}$ [61]. In this cycle, APX can scavenge $\mathrm{H}_{2} \mathrm{O}_{2}$ followed by a series of catalytic reactions involving GR, MDHAR and DHAR, in which GSH and AsA work as reducing substrates [62]. Adding SWCNTs increased GSH contents. Expression levels of GPX and GR in SWCNTs-added cryopreservation were lower than those in the control group, and the difference between these two processes became very obvious after rapid cooling-warming. This study indicated that PVS2 with SWCNTs improved the survival of Agapanthus praecox. SWCNTs promoted dehydration protection, and this improvement is due to the scavenging of ROS and improving of antioxidative system activity, especially POD and CAT.

\section{Effects of SWCNTs on ROS signal transduction during cryopreservation}

Because of their key signaling roles (at low levels) and toxic roles (at high levels), the levels of ROS are regulated by the complex pathway including many genes [63-65]. In this pathway, plants sense ROS by three ways: (a) unknown ROS receptors; (b) redox-sensitive transcription factors; (c) direct inhibition of phosphatases [66]. The ROS signal is detected by unknown ROS receptors leading to the accumulation of $\mathrm{Ca}^{2+}$ signal [67-69], and the signal is transmitted to oxidative signal-inducible 1 (serine/threonine protein kinase, OXI1) which was significantly upregulated in the control rapid cooling-warming with ROS level reaching the maximum which is much higher than that in the SWCNTs-added cryopreservation. OXI1 acts as a central factor in the ROS sensing, and is upregulated in many $\mathrm{H}_{2} \mathrm{O}_{2}$-generating stimulus [70].
MAPK3/6 following OXI1 [71, 72] were mainly upregulated during rapid cooling-warming of the control group.

The ROS signals further influenced following pathways including ROS producing and scavenging. The producing pathway has NADPH oxidases [73, 74], which were upregulated in the SWCNTs-treated steps. The producing pathway might be activated by ROS at low levels leading to the ROS production and amplification, and the scavenging pathway might be activated by ROS accumulation leading to the ROS suppression [66]. The interaction between the producing and scavenging pathway determines the intensity of ROS signals [66]. In summary, $\mathrm{EC}$ in the control group suffered excessive ROS after dehydration, which broke the ROS metabolism balance. By contrast, SWCNTs both enhanced the producing and scavenging pathway smoothly, and maintained ROS signals balanced and stable in EC during cryopreservation.

\section{Regulation of the physiological response by carbon nanotubes in plants}

In the past decade, researchers have applied carbon nanotubes to plant studies and found that they have a certain regulatory effect on the physiological response, especially on enzyme activity and gene expression. The effective impact of CNMs on plant development and growth has been studied by many research groups [75]. Giraldo et al. [76] pointed out that SWCNTs localized in the lipid envelope of Arabidopsis chloroplasts, promoted over three times higher photosynthetic activity than that of controls, and concentrations of ROS inside chloroplasts were significantly suppressed. Industrialized MWCNTs can stimulate the growth of Onobrychis arenaria and enhance peroxidase activity [77]. In this study, SWCNTs contributed to the better efficiency of the cryoprotectant, and also improved enzyme activities including POD and CAT. At the molecular level, SWCNTs regulated gene expression levels including $N A D P H$ oxidase, $C A T$ and $P O D$. Other studies have found the similar results. The MWCNTs enhanced the tobacco cell growth, and upregulated genes related to water transport and cell division [78]. A number of genes regulated by MWCNTs were related to plant stress-signal transduction in tomato. Important stress signal pathways could be regulated in response to the uptake of carbon nanotubes [79]. For instance, MAPK was upregulated in leaves exposed to MWCNTs, and played a positive role in promoting plant development and stress response of carbon nanotubes [79]. In this study, MAPK3/6 were higher in the control rapid cooling-warming than those treated with SWCNTs. Adding MWCNTs to the seeds of soybean (Glycine max), corn (Zea mays) and barley (Hordeum vulgare) led to the improvement of germination, and activated expression levels of aquaporins [80]. 
On the contrary, experiment on suspension rice cells with MWCNTs showed that it induced the accumulation of ROS leading to cell death [81]. It also decreases the dry weight and the SOD activity in Arabidopsis suspension cells [82]. Whether carbon nanotubes play a positive or negative regulatory role, they can regulate a variety of biological processes in plants, like water transport, cell division, stress response, electron transfer, ROS generation, and metabolism [83, 84]. However, the mechanism of how the nanotubes can regulate the physiological response especially regulate the gene expression is still an unresolved issue and deserved further studies.

\section{Conclusions}

This study found that the relative survival rate was highly improved by adding SWCNTs to PVS2 in cryopreservation of $A$. praecox $\mathrm{EC}$, and analyzed the oxidative response of EC at some steps in the control and SWCNTs-added cryopreservation. The SWCNTs entered EC at the step of dehydration, and mainly located around the cell wall and in the vesicles, and most of SWCNTs moved out of EC during the dilution step. The SWCNTs affected the ROS signal transduction pathway and antioxidant system response through the physiological and gene expression results. The EC treated with SWCNTs exhibited higher antioxidant levels, including POD, CAT and GSH than the EC in the control group. The EC mainly depended on the GPX and AsA-GSH cycle to scavenge $\mathrm{H}_{2} \mathrm{O}_{2}$ in the control cryopreservation, but depended on CAT in the SWCNTs-added cryopreservation which led to low levels of $\mathrm{H}_{2} \mathrm{O}_{2}$ and MDA. The elevated antioxidant level in dehydration by adding SWCNTs improved cells tolerance to injury from the cryopreservation procedure. The ROS signals of EC were balanced and stable in the SWCNTs-added cryopreservation. Overall, SWCNTs regulated the oxidative stress response of EC in cryopreservation and controlled cell oxidative injury by keeping ROS homeostasis to achieve a high survival rate after cryopreservation.

\section{Methods}

\section{Plant material}

The EC was induced and cultured from pedicel tissue of $A$. praecox as described by Wang et al. [34], and was maintained at $25 \pm 2{ }^{\circ} \mathrm{C}$ in the dark by subculturing monthly onto the MS medium supplemented with $1.5 \mathrm{mg} / \mathrm{L}$ picloram. After 14 days of subculture, $0.2 \mathrm{~g}$ of EC was used as the replication for subsequent experiments.

\section{Experimental design}

$0.2 \mathrm{~g}$ of EC was cryopreserved as described by Chen et al. [30]. The cryopreservation procedure included pre-culture (PC), osmoprotection (OP), dehydration with PVS2 (DH), rapid cooling-warming (RW), dilution (DL), and recovery (RC) (Fig. 6). The SWCNTs aqueous solution $(5.0 \mathrm{~g} / \mathrm{L}$, particle diameter $1 \mathrm{~nm}$, length $1 \mu \mathrm{m})$ was kindly provided by Prof. Yafei Zhang (Shanghai Jiao Tong University, Shanghai, China). In the SWCNTsadded cryopreservation procedure, we added SWCNTs at $0.1 \mathrm{~g} / \mathrm{L}$ in PVS2 at the dehydration step. The EC as samples for the physiological experiments and qRTPCR analysis were taken after some key steps including $\mathrm{CK}, \mathrm{PC}, \mathrm{DH}, \mathrm{RW}$, and DL in the control and SWCNTsadded cryopreservation (Fig. 6). Experiments were performed three times individually.

\section{Viability detection}

In order to detect the survival of cryopreserved EC, the 2,3,5-triphenyltetrazolium chloride (TTC) protocol was used in this study [30]. The EC (0.05 g) after 24 h-recovery was put into $2 \mathrm{~mL}$ TTC and kept in the dark for $20 \mathrm{~h}$. After rinsing 3 times with sterile water, EC was immersed in $95 \%$ ethanol and $85{ }^{\circ} \mathrm{C}$ water bathed for $1 \mathrm{~h}$. The EC was centrifuged at $3000 \mathrm{~g}$ for $5 \mathrm{~min}$, and the optical density value of supernatant was tested at $485 \mathrm{~nm}$. The relative survival rate was the ratio of cryopreserved and non-cryopreserved value. Each sample procedure was repeated 3 times.

\section{Transmission electron microscopy}

The EC $(0.05 \mathrm{~g})$ was treated as described by Chen et al. [28], and observed by $120 \mathrm{kV}$ biology transmission electron microscope (Tecnai G2 spirit Biotwin).

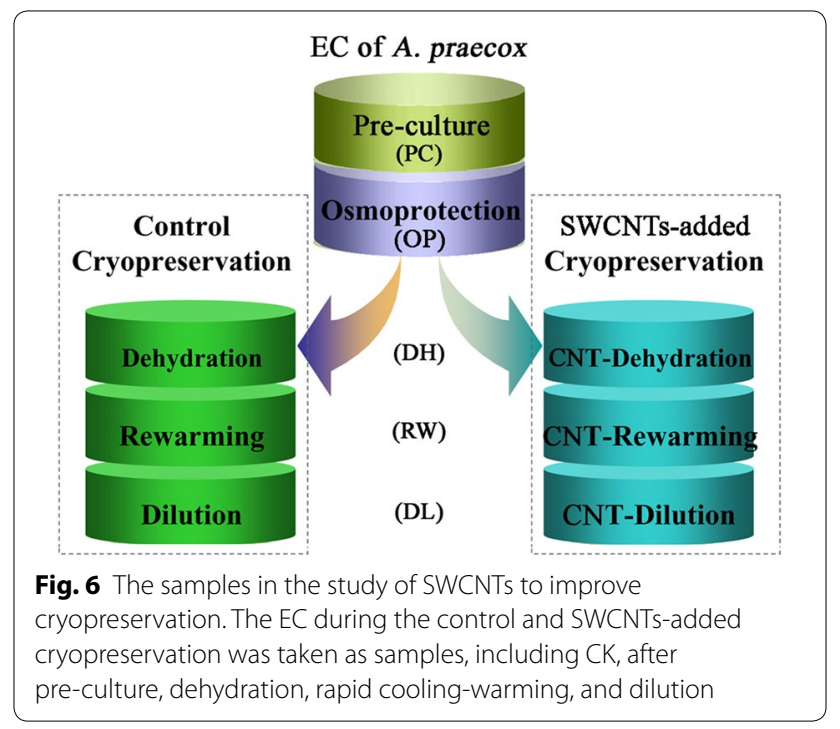




\section{Detection of physiological indices}

The EC $(0.2 \mathrm{~g})$ was used to detect the physiological indices. $\mathrm{H}_{2} \mathrm{O}_{2}$ levels, $\mathrm{O}_{2}{ }^{-}$inhabitation and $\mathrm{OH}$. generation activities, MDA content, SOD, CAT and POD activities, AsA and GSH contents were tested using the related biological assay kits (Nanjing Jiancheng Bioengineering Institute, China) following the manufacturer's instructions with some modifications according to Yang et al. [85].

\section{qRT-PCR analysis}

The qRT-PCR was performed as described by Chen et al. [30]. The EC $(0.1 \mathrm{~g})$ was collected for total RNA extraction using MiniBEST plant RNA extraction kit (TaKaRa, Otsu, Shiga, Japan) according to the manufacturer's instructions. The amplifications were repeated for 3 times. The relative quantitative expression was calculated using the $2^{-\triangle \triangle \mathrm{CT}}$ method. The actin was used as an internal control parameter for normalization, and all primer sequences were listed in Additional file 1: Table $\mathrm{S} 1$ including $A P X, C A T, F e S O D, C u / Z n S O D, P O D$, MDHAR, GPX1, GR, NADPH oxidase, OXI1, MAPK3, and MAPK6. The heat-map figures were made by GENESIS Software after the normalization of gene expression data.

\section{Statistical analysis}

The one-way ANOVA was used to analyze differences followed by the least significant difference multiple range test using Statistics Analysis System 9.1.3 software (SAS Institute, Inc., Cary, NC, USA). Correlation analysis was calculated by Statistics Analysis System 9.1.3 software, and $\mathrm{P}<0.05$ was considered as significant.

\section{Supplementary information}

Supplementary information accompanies this paper at https://doi. org/10.1186/s13007-020-00674-6.

Additional file 1: Table S1. Primers sequences of qRT-PCR.

\footnotetext{
Abbreviations

ABA: Abscisic acid; APX: Ascorbate peroxidase; AsA: Ascorbic acid; CAT : Catalase; CNMs: Carbon nanomaterials; CNTs: Carbon nanotubes; CW: Cell wall; DH: Dehydration; DHAR: Dehydroascorbate reductase; DL: Dilution; DSC: Differential scanning calorimetry; EC: Embryogenic callus; ER: Endoplasmic reticulum; G: Golgi apparatus; GPX: Glutathione peroxidase; GR: glutathione reductase; GSH: Glutathione; $\mathrm{H}_{2} \mathrm{O}_{2}$ : Hydrogen peroxide; LA: Lipoic acid; LB: Lipid body; LN: Liquid nitrogen; LSD: Least significant difference; M: Mitochondrion; MAPK: Mitogen-activated protein kinase; MDA: Malonaldehyde; MDHAR: Monodehydroascorbate reductase; MS: Murashige and Skoog; NRSP: Nanomaterials Rhodiola Sachanensis Polysaccharide; $\mathrm{O}_{2}^{-}$: Superoxide anion; OH: Hydroxyl radicals; OP: Osmoprotection; OXI1: Oxidative signal-inducible 1; PC: Pre-culture; PVA: polyvinyl alcohol; PVP: Polyvinyl pyrrolidone; PVS: Plant vitrification solution; qRT-PCR: Quantitative reverse-transcription polymerase
}

chain reactions; RC: Recovery; ROS: Reactive oxygen species; RW: Rapid cooling-warming; SG: Starch grains; SOD: Superoxide dismutase; SWCNTs: Single-wall carbon nanotubes; TEM: Transmission electron microscopy; TTC: Triphenyltetrazolium chloride; VES: Vesicle.

\section{Acknowledgements}

The authors thank Prof. Yafei Zhang (Shanghai Jiao Tong University, Shanghai, China) for providing the SWCNTs aqueous solution.

\section{Authors' contributions}

$\mathrm{HC}$ and DZ conceived and designed research. LR and SD conducted experiments. YC, YZ and $\mathrm{HZ}$ analyzed the data. LR was a major contributor in writing the manuscript. All authors read and approved the final manuscript.

\section{Funding}

This work was supported by the National Natural Science Foundation of China [Nos. 31870686, 31670693 and 31971705], and Academic Specialty Development Project of Shanghai Academy of Agricultural Sciences (2019-13).

\section{Availability of data and materials}

All data generated or analysed during this study are included in this published article and its Additional file 1:Table S1.

\section{Ethics approval and consent to participate}

Not applicable.

\section{Consent for publication}

Not applicable.

\section{Competing interests}

The authors declare that they have no competing interests.

Received: 10 May 2020 Accepted: 15 September 2020

Published online: 21 September 2020

\section{References}

1. Reed BM. Plant cryopreservation: a continuing requirement for food and ecosystem security. Vitro Cell Dev. 2017;53:285-8.

2. Sakai A. Survival of the twigs of woody plants at $-196^{\circ} \mathrm{C}$. Nature. 1960;185:392-4.

3. Engelmann F. Cryopreservation: progress and prospects. Vitro Cell Dev. 2004;40:427-33.

4. Wang MR, Yang W, Zhao L, Li JW, Liu K, Yu JW, Wu YF, Wang QC. Cryopreservation of virus: a novel biotechnology for long-term preservation of virus in shoot tips. Plant Methods. 2018;14:47.

5. Sakai A, Hirai D, Niino T. Development of PVS-based vitrification and encapsulation-vitrification protocols. In: Reed BM, editor. Plant cryopreservation: a practical guide. New York: Springer-Verlag; 2008. p. 33-57.

6. Volk GM, Walters C. Plant vitrification solution 2 lowers water content and alters freezing behaviour in shoot tips during cryoprotection. Cryobiology. 2006;52:48-61

7. Ren L, Zhang D, Jiang X, Gai Y, Wang W, Reed BM, Shen X. Peroxidation due to cryoprotectant step is a vital factor for cell survival in Arabidopsis cryopreservation. Plant Sci. 2013;212:37-47.

8. Benson EE. Free radical damage in stored plant germplasm. Italy: International board for plant genetic resources; 1990.

9. Ren L, Zhang D, Chen G, Reed BM, Shen X, Chen H. Transcriptomic profiling revealed the regulatory mechanism of Arabidopsis seedlings response to oxidative stress from cryopreservation. Plant Cell Rep. 2015;34:2161-78.

10. Zhang D, Ren L, Chen G, Zhang J, Reed BM, Shen X. ROS-induced oxidative stress and apoptosis-like event directly affect the cell viability of cryopreserved embryogenic callus in Agapanthus praecox. Plant Cell Rep. 2015;34:1499-513.

11. Gill SS, Tuteja N. Reactive oxygen species and antioxidant machinery in abiotic stress tolerance in crop plants. Plant Physiol Bioch. 2010;48:909-30. 
12. Volk GM. Application of functional genomics and proteomics to plant cryopreservation. Curr Genomics. 2010;11:24-9.

13. Van Breusegem F, Vranová E, Dat JF, Inzé D. The role of active oxygen species in plant signal transduction. Plant Sci. 2001;161:405-14.

14. Scandalios JG. Molecular genetics of SOD in plants. In: Scandalios JG, editor. Oxidative stress and the molecular biology of antioxidant defense. Cold Spring Harbor: Cold Spring Harbor Laboratory Press; 1997. p. 527-68.

15. Meyer AJ. The integration of glutathione homeostasis and redox signaling. J Plant Physiol. 2008;165:1390-403.

16. Husen A, Siddiqi KS. Carbon and fullerene nanomaterials in plant system. J Nanobiotech. 2014;12:1-10.

17. Hao BT. Application of nanopaticles in cell cryopreservation. J Clin Rehabilita Tiss Eng Res. 2008;12:8140-2.

18. Derui DI, Zhizhu HE, Liu J. Advances in nano-cryopreservation of biological materials. Ciesc J. 2011;62:1781-9.

19. LiW, Zhou X, LV F, Liu B. Preliminary study on the mechanism of promoting the survival rate of vitrified oocytes with nano-cryoprotectants. J Refrigeration. 2014;35:114-8.

20. Han X, Ma HB, Wilson C, Critser JK. Effects of nanoparticles on the nucleation and devitrification temperatures of polyol cryoprotectant solutions. Microfluid Nanofluid. 2008:4:357-61.

21. Li W, Zhou XL, Liu BL, Dai JJ, Lv FK, Zhang DF, Xu L. The effect of nanoparticle on vitrification of porcine GV-stage oocytes. Chin J Biomed Eng. 2013;32:601-5.

22. Han X, Dai JJ, Zhang SS, Zhang TY, Wu CF, Gu XL, Li X, Xu L, Li FF, Zhang DF. Effects of nonomaterials rhodiola sachalinensis polysaccaride on cryopreservation of boar semen. Chin J Vet Sci. 2013;33:1937-42.

23. Nadri T, Towhidi A, Zeinoaldini S, Martínez-Pastor F, Mousavi M, Noei R, Tar M, Mohammadi Sangcheshmeh A. Lecithin nanoparticles enhance the cryosurvival of caprine sperm. Theriogenology. 2019;133:38-44.

24. Dashtestani F, Ghourchian H, Najafi A. Albumin coated copper-cysteine nanozyme for reducing oxidative stress induced during sperm cryopreservation. Bioorg Chem. 2018;80:621-30.

25. Dashtestani F, Ghourchian H, Najafi A. Silver-gold-apoferritin nanozyme for suppressing oxidative stress during cryopreservation. Mat Sci Eng $C$ Mater. 2019;94:831-40.

26. Khalil WA, El-Harairy MA, Zeidan AEB, Hassan MAE. Impact of selenium nano-particles in semen extender on bull sperm quality after cryopreservation. Theriogenology. 2019;126:121-7.

27. Zhang J, Yang K, Zhang H, Liang X. Application status and prospect of carbon-based nanomaterials in biomedical field. Prog Chem. 2013:25:397-408.

28. Chen SM, Ren L, Zhang D, Zhang YF, Shen XH. Carbon nanomaterials enhance survival of Agapanthus praecox callus after cryopreservation by vitrification. Cryo Lett. 2017;38:125-36.

29. Zhang D, Ren L, Yue J, Wang L, Zhuo L, Shen X. A comprehensive analysis of flowering transition in Agapanthus praecox ssp. orientalis (Leighton) Leighton by using transcriptomic and proteomic techniques. J Proteomics. 2013;80:1-25.

30. Chen GQ, Ren L, Zhang D, Shen XH. Glutathione improves survival of cryopreserved embryogenic calli of Agapanthus praecox subsp. orientalis. Acta Physiol Plant. 2016:38:250.

31. Zhang $D$, Ren L, Shen XH, Zhuo LH. Fertilization and embryogenesis in Agapanthus praecox ssp. orientalis (Leighton) Leighton. Plant Syst Evol. 2011;293:25-30

32. Baskaran P, Chukwujekwu JC, Amoo SO, Van Staden J. Anticholinesterase and mutagenic evaluation of in vitro-regenerated Agapanthus praecox grown ex vitro. Vitro Cell Dev. 2014;50:271-5.

33. Suzuki S, Oota M, Nakano M. Embryogenic callus induction from leaf explants of the Liliaceous ornamental plant, Agapanthus praecox ssp. orientalis (Leighton) Leighton Histological study and response to selective agents. Sci Hortic. 2002;95:123-32.

34. Wang Y, Fan X, Zhang D, Shen X. Regeneration of Agapanthus praecoX ssp. orientalis'big blue'via somatic embryogenesis. Propag Ornam Plants. 2012:12:148-54

35. Baskaran P, Van Staden J. Rapid in vitro micropropagation of Agapanthus praecox. S Afr J Bot. 2013:86:46-50

36. Wang ZC, Deng XX. Cryopreservation of shoot-tips of citrus using vitrification: effect of reduced form of glutathione. Cryo Lett. 2004;25:43-50.
37. Uchendu EE, Leonard SW, Traber MG, Reed BM. Vitamins C and E improve regrowth and reduce lipid peroxidation of blackberry shoot tips following cryopreservation. Plant Cell Rep. 2010;29:25-35.

38. Uchendu EE, Muminova M, Gupta S, Reed BM. Antioxidant and anti-stress compounds improve regrowth of cryopreserved Rubus shoot tips. Vitro Cell Dev Biol. 2010;46:386-93.

39. Zhao Y, Qi LW, Wang WM, Saxena PK, Liu CZ. Melatonin improves the survival of cryopreserved callus of Rhodiola crenulata. J Pineal Res. 2011:50:8-88.

40. Hu MJ. Cryopreservation of Arabidopsis thaliana suspension cells and the role of Abscisic Acid in stress signaling transduction pathways. Dissertation, Zhejiang University, 2003.

41. Lardet L, Martin F, Dessailly F, Carron MP, Montoro P. Effect of exogenous calcium on post-thaw growth recovery and subsequent plant regeneration of cryopreserved embryogenic calli of Hevea brasiliensis (Müll. Arg.) Plant Cell Rep. 2007;26:559-69.

42. Ryynanen L, Haggman H. Recovery of cryopreserved silver birch shoot tips is affected by the pre-freezing age of the cultures and ammonium substitution. Plant Cell Rep. 2001;20:354-60.

43. Decruse SW, Seeni S, Nair GM. Preparative procedures and culture medium affect the success of cryostorage of Holostemma annulare shoot tips. Plant Cell Tiss Org. 2004;76:179-82.

44. Kami D, Kasuga J, Arakawa K, Fujikawa S. Improved cryopreservation by diluted vitrification solution with supercooling-facilitating flavonol glycoside. Cryobiology. 2008;57:242-5.

45. Wang HY, Inada T, Funakoshi K, Lu SS. Inhibition of nucleation and growth of ice by poly (vinyl alcohol) in vitrification solution. Cryobiology. 2009;59:83-9.

46. Johnston JW, Harding K, Benson EE. Antioxidant status and genotypic tolerance of Ribes in vitro cultures to cryopreservation. Plant Sci. 2007:172:524-34

47. Fang JY, Wetten A, Johnston J. Headspace volatile markers for sensitivity of cocoa (Theobroma cacao L.) somatic embryos to cryopreservation. Plant Cell Rep. 2008;27:453-61.

48. Whitaker C, Beckett RP, Minibayeva FV, Kranner I. Production of reactive oxygen species in excised, desiccated and cryopreserved explants of Trichilia dregeana Sond. S Afr J Bot. 2010;76:112-8.

49. Skyba M, Petijová L, Košuth J, Koleva DP, Ganeva TG, Kapchina-Toteva VM, Cěllárová E. Oxidative stress and antioxidant response in Hypericum perforatum L. plants subjected to low temperature treatment. J Plant Physiol. 2012;169:955-64.

50. Chen GQ, Ren L, Zhang J, Reed BM, Zhang D, Shen XH. Cryopreservation affects ROS-induced oxidative stress and antioxidant response in Arabidopsis seedlings. Cryobiology. 2015;70:38-47.

51. Jia MX, Shi Y, Di W, Jiang XR, Xu J, Liu Y. ROS-induced oxidative stress is closely related to pollen deterioration following cryopreservation. Vitro Cell Dev Biol-PI. 2017:53:433-9.

52. Huang $B$, Zhang JM, Chen XL, Xin X, Yin GK, He JJ, Lu XX, Zhou YC. Oxidative damage and antioxidative indicators in $48 \mathrm{~h}$ germinated rice embryos during the vitrification-cryopreservation procedure. Plant Cell Rep. 2018:37:1325-42

53. Vianna MG, Garcia RO, Mansur E, Engelmann F, Pacheco G. Oxidative stress during the cryopreservation of Passiflora suberosa L. shoot tips using the V-Cryo-plate technique: determination of the critical stages of the protocol. Plant Cell Tiss Org. 2019;139:369-79.

54. Benson EE, Bremner D. Oxidative stress in the frozen plant: a free radical point of view. In: Fuller BJ, Lane N, Benson EE, editors. Life in the frozen state. Boca Raton: CRC Press; 2004. p. 205-41.

55. Benson EE, Lynch PT, Jones J. The detection of lipid peroxidation products in cryoprotected and frozen rice cells - consequences for post thaw survival. Plant Sci. 1992;85:107-14

56. Varghese B, Naithani SC. Oxidative metabolism-related changes in cryogenically stored neem (Azadirachta indica A. Juss) seeds. J Plant Physiol. 2008:165:755-65.

57. Prudente DO, Paiva R, Nery FC, Paiva PDO, Alves JD, Máximo WPF, Silva LC. Compatible solutes improve regrowth, ameliorate enzymatic antioxidant systems, and reduce lipid peroxidation of cryopreserved Hancornia speciosa Gomes lateral buds. Vitro Cell Dev Biol. 2017;53:352-62.

58. Poobathy R, Sinniah UR, Xavier R, Subramaniam S. Catalase and superoxide dismutase activities and the total protein content of protocorm-like 
bodies of Dendrobium Sonia-28 subjected to vitrification. Appl Biochem Biotechnol. 2013;170:1066-79.

59. Fleck RA, Benson EE, Bremner DH, Day JG. A comparative study of antioxidant protection in cryopreserved unicellular algae Euglena gracilis and Haematococcus pluvialis. Cryo-lett. 2003;24:213-28.

60. Liu SJ. The effects of graphene on the germination and seedling growth in rice. Yangtze University, 2013.

61. Noctor G, Foyer $\mathrm{CH}$. Ascorbate and glutathione: keeping active oxygen under control. Annu Rev Plant Physiol Plant Mol Biol. 1998;49:249-79.

62. Alscher RG, Donahue JL, Cramer CL. Reactive oxygen species and antioxidants: relationships in green cells. Physiol Plant. 1997;100:224-33.

63. Dat JF, Vandenabeele S, Vranová E, Van Montagu M, Inzé D, Van Breusegem F. Dual action of the active oxygen species during plant stress responses. Cell Mol Life Sci. 2000;57:779-95.

64. Mittler R. Oxidative stress, antioxidants and stress tolerance. Trends Plant Sci. 2002; 7:405-10

65. Vranová E, Atichartpongkul S, Villarroel R, Van Montagu M, Inzé D, Van Camp W. Comprehensive analysis of gene expression in Nicotiana tabacum leaves acclimated to oxidative stress. Proc Natl Acad Sci USA. 2002:99:10870-5

66. Mittler R, Vanderauwera S, Gollery M, Van Breusegem F. Reactive oxygen gene network of plants. Trends Plant Sci. 2004;9:490-8.

67. Bowler C, Fluhr R. The role of calcium and activated oxygens as signals for controlling cross-tolerance. Trends Plant Sci. 2000;5:241-6.

68. Knight $H$, Knight MR. Abiotic stress signalling pathways: specificity and cross-talk. Trends Plant Sci. 2001;6:262-7.

69. Coelho SM, Taylor AR, Ryan KP, Sousa-Pinto I, Brown MT, Brownlee C Spatiotemporal patterning of reactive oxygen production and $\mathrm{Ca}^{2+}$ wave propagation in Fucus rhizoid cells. Plant Cell. 2002;14:2369-81.

70. Rentel MC, Lecourieux D, Ouaked F, Usher SL, Petersen L, Okamoto $\mathrm{H}$, Knight $\mathrm{H}$, Peck SC, Grierson CS, Hirt H, Knight MR. OXI1 kinase is necessary for oxidative burst-mediated signalling in Arabidopsis. Nature. 2004:427:858-61.

71. Kovtun Y, Chiu WL, Tena G, Sheen J. Functional analysis of oxidative stress activated mitogen-activated protein kinase cascade in plants. Proc Natl Acad Sci USA. 2000;97:2940-5.

72. Apel K, Hirt H. Reactive oxygen species: metabolism, oxidative stress, and signal transduction. Annu Rev Plant Biol. 2004:55:373-99.

73. Dat JF, Pellinen R, Beeckman T, Van De Cotte B, Langebartels C, Kangasjärvi J, Inzé D, Van Breusegem F. Changes in hydrogen peroxide homeostasis trigger an active cell death process in tobacco. Plant J. 2003:33:621-32.

74. Rizhsky L, Davletova S, Liang HJ, Mittler R. The zinc finger protein Zat12 is required for cytosolic ascorbate peroxidase 1 expression during oxidative stress in Arabidopsis. J Biol Chem. 2004;279:11736-43.
75. Zaytseva O, Neumann G. Carbon nanomaterials: production, impact on plant development, agricultural and environmental applications. Chem Biol Technol Agric. 2016:3:17.

76. Giraldo JP, Landry MP, Faltermeier SM, McNicholas TP, Iverson NM, Boghossian AA, Reuel NF, Hilmer AJ, Sen F, Brew JA, Strano MS. Plant nanobionics approach to augment photosynthesis and biochemical sensing. Nat Mater. 2014;13:400-8.

77. Elena S, Gusev A, Zaytseva O, Sheina O, Tkachev A, Kuznetsova E, Lazareva E, Onishchenko G, Feofanov A, Kirpichnikov M. Uptake and accumulation of multiwalled carbon nanotubes change the morphometric and biochemical characteristics of Onobrychis arenaria seedlings. Fron Chem Sci Eng. 2012;6:132-8.

78. Khodakovskaya MV, De Silva K, Biris AS, Dervishi E, Villagarcia H. Carbon nanotubes induce growth enhancement of tobacco cells. ACS Nano. 2012;6:2128-35.

79. Khodakovskaya M, De Silva K, Nedosekin D, Dervishi E, Biris AS, Shashkov EV, Galanzha El, Zharov VP. Complex genetic, photothermal, and photoacoustic analysis of nanoparticle-plant interactions. Proc Natl Acad Sci USA. 2011;108:1028-33.

80. Lahiani MH, Dervishi E, Chen J, Nima Z, Gaume A, Biris AS, Khodakovskaya MV. Impact of carbon nanotube exposure to seeds of valuable crops. ACS Appl Mater Inter. 2013;5:7965-73.

81. Tan X, Lin C, Fugetsu B. Studies on toxicity of multi-walled carbon nanotubes on suspension rice cells. Carbon. 2009;47:3479-87.

82. Lin C, Fugetsu B, Su Y, Watari F. Studies on toxicity of multi-walled carbon nanotubes on Arabidopsis T87 suspension cells. J Hazard Mater. 2009;170:578-83.

83. Aslani F, Bagheri S, Julkapli NM, Juraimi AS, Hashemi FSG. Baghdadi A. Effects of engineered nanomaterials on plants growth: An overview. Sci World J; 2014. p. 641759.

84. Husen A, Siddiqi KS. Carbon and fullerene nanomaterials in plant system. J Nanobiotechnol. 2014;12:16.

85. Yang Z, Sheng J, Lv K, Ren L, Zhang D. Y $S_{2} K_{2}$ and $\mathrm{SK}_{3}$ type dehydrins from Agapanthus praecox can improve plant stress tolerance and act as multifunctional protectants. Plant Sci. 2019;284:143-60.

\section{Publisher's Note}

Springer Nature remains neutral with regard to jurisdictional claims in published maps and institutional affiliations.
Ready to submit your research? Choose BMC and benefit from:

- fast, convenient online submission

- thorough peer review by experienced researchers in your field

- rapid publication on acceptance

- support for research data, including large and complex data types

- gold Open Access which fosters wider collaboration and increased citations

- maximum visibility for your research: over 100M website views per year

At BMC, research is always in progress.

Learn more biomedcentral.com/submissions 